\title{
The moral status of the (nuclear) family
}

\author{
Daniela Cutas* \& Anna Smajdor**
}

*Umeå University, Department of Historical, Philosophical and Religious Studies and University of Gothenburg, Department of Philosophy, Linguistics and Theory of Science, daniela.cutas@umu.se

${ }^{* *}$ University of Oslo, Department of Philosophy, Classics, History of Art and Ideas, anna.smajdor@ifikk.uio.no

DOI: http://dx.doi.org/10.5324/eip.v11i1.2250

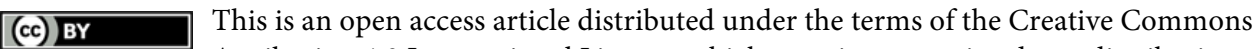
Attribution 4.0 International License, which permits unrestricted use, distribution, and reproduction in any medium, provided the original author and source are credited.

The family is commonly regarded as being an important social institution. In several policy areas, evidence can be found that the family is treated as an entity towards which others can have moral obligations; it has needs and interests that require protection; it can be ill and receive treatment. The interests attributed to the family are not reducible to those of its members - and may even come into conflict with them. Using Warren's criteria for moral status, we show that, although the family is not explicitly described in terms of moral status, the way in which it is treated implies that it has such status.

Keywords: family, childhood, moral status, conceptual entities, infertility

\section{Introduction}

Beliefs in the value of the family and the moral status of children, women or other entities, have evolved over time. In Western democracies, certain core values are associated with families. The family is treated by many liberal political theories as an entity that needs protection from the control of state authorities. In practice, this has meant that families fall under the authority of their most powerful members. The privacy-type protections that states can guarantee to families thus do not protect or benefit all individual members of those families equally. Rather, as Okin has pointed out, they secure the political existence of the family as a domain in which some individuals can exercise their power over others with relatively little risk of interference (Okin 1989). Although almost three decades have passed since Okin made these observations, this is largely still the case today.

Historically, women have suffered as a result of their position within the family and associated expectations that they must prioritise the family's interests above their own. With the development of women's rights and increasing respect for gender equality, women are less vulnerable in the family than they used to be. Societal views about the value of children and childhood have also changed dramatically in recent decades (DeMause 1974, Brennan and Noggle 1997). However, children remain vulnerable in the family. To some extent, this is inescapable, since children's vulnerability is not primarily the product of social and 
political attitudes as is that of women. Rather, it is an integral part of the nature of childhood.

Human rights documents, such as the UN Convention on the Rights of the Child, frame societal concern for children in terms of "the best interests of the child", which should be "a primary consideration" (United Nations 1989, Art 3). Families are often regarded as a necessary structure for the protection of children. However, as we will show, the implicit tendency to value families in a way that is consistent with their having moral status is widespread in several societal and policy areas. It then becomes possible for the interests of the family to supersede those of its individual members. This gives rise to a need to critically evaluate the implications of such attitudes, and their underlying moral implications.

We suggest that children - and women - in the family are still often more vulnerable than their intrinsic biological circumstances warrant, specifically because of the high regard in which we hold families per se. Even though members of a family may not be equally vulnerable, in fact the status ascribed to the family as an entity in its own right may mean that any of its members are at risk when their interests are subsumed into those of the family. We analyse the moral status ascribed to the (nuclear) family in relation to that ascribed to its members in contemporary Western society. Is the family upheld in a way that is consistent with it being deemed as having moral status in and of itself? If so, what does this imply for the moral status of its members? In order to investigate these questions, we first look at a prominent account of moral status in the philosophical literature. We then look at different concepts of the family and go on to show how the family is treated as an entity that can suffer from a disease (infertility). We then provide further examples to illustrate our claim that the family, as it is currently construed, fits a general description as a holder of moral status beyond - and even in conflict with that of its members.

In this paper, we do not endorse the view that conceptual entities have moral status or that the family specifically has such status - nor do we view our criticism of ascribing moral status to conceptual entities as sufficient to refute such an ascription. We acknowledge that the claim that conceptual entities have moral status is controversial, but for the purposes of this paper it suffices to show that the treatment of the family is in line with how other conceptual entities are treated when they are ascribed moral status. What we aim to do is to show that the value that is awarded the family is consistent with it having moral status - sometimes to a degree beyond the moral status of its members. Lastly, although we criticise some of the ways in which the value of the family is upheld, our analysis is not meant as a criticism of the value of the family per se. Others have very aptly highlighted the value of the family in spite of its challenges, especially given its alternatives (MunozDardé 1999, Gheaus 2017). Rather, we suggest that the status of the family can, and perhaps should, be adjusted to reduce the vulnerability of its members.

\section{What is moral status and who has it?}

One of the most prominent accounts of moral status in the philosophical literature was developed by Mary Anne Warren. According to this account, to have moral status 
is to be morally considerable, or to have moral standing. It is to be an entity ${ }^{1}$ towards which moral agents have, or can have, moral obligations. If an entity has moral status, then we may not treat it in just any way we please; we are morally obliged to give weight in our deliberations to its needs, interests, or well-being. Furthermore, we are morally obliged to do this not merely because protecting it may benefit ourselves or other persons, but because its needs have moral importance in their own right (Warren 1997: 3).

Moral agents are those individuals who bear responsibility for their actions, because they have the capacity to reason and make decisions based on reasons. Moral agents have an obligation to regulate their actions in accordance with the moral status of others. For example, we could say that a lion has moral status and should be considered for its own sake, but a lion is not a moral agent, because it lacks the capacity for rational deliberation that is characteristic of entities with moral agency. Furthermore, it has been suggested that moral agents have full, rather than merely partial, moral status. This full moral status

is understood to involve (i) a very stringent moral presumption against the interfering with the being in various ways - destroying the being, experimenting upon it, directly causing its suffering, etc. (...) (ii) a strong, but not necessarily stringent, reason to aid and (iii) a strong reason to treat fairly (Stanford Encyclopedia of Philosophy 2013).

Family members may or may not have full moral status in this sense. For example, children's moral agency depends on their age and capacities, and as we have seen above, full moral status has been correlated with moral agency. Thus, from this perspective, children have less than full moral status. Philosophers such as Aristotle, Hume, Kant, Schopenhauer and others were happy to bar women from being ascribed full moral status, on grounds that they were less capable of moral agency (Warren 1997: 7). However, regardless of the degree of moral agency that they may possess, family members are now seen, both in philosophical scholarship and outside of it, as morally considerable: they have moral status in Warren's sense. The question in this paper is whether the family itself also has such status and if so, whether the moral status of the family and that of its members are compatible.

\section{The moral status of conceptual entities}

As we will illustrate further on, the family tends to be regarded as something that should be protected. This may not in itself be problematic, but it leads to a possibility that the interests of the conceptual entity that is the family may conflict with those of individuals who are not merely conceptual, but who have the capacity to suffer, to be exploited, or treated unjustly. Normally, when we speak of something being good or bad, we mean that they are good or bad for someone. The idea of the family is itself an abstraction: a social construct. And while of course it is practical to have a concept of the family, it seems important to remember that unless one adheres to a very Platonic kind of philosophy - there is no entity that is the family. There are only particular human beings.

Debates about moral status typically revolve around questions of our treatment of embryos, fetuses, or animals. Environmental ethicists have been concerned with the moral status of conceptual entities for some time. Some regard only individual organisms as having moral value or interests (Taylor 1986, Varner 1998). However, 
others apply the idea of moral status more broadly to encompass nature itself, as well as sub-classifications such as ecosystems and species (Rolston 2002). As soon as we recognise the existence of conceptual entities and ascribe interests to them, the possibility arises that particular individuals' interests might be subsumed into the interests of this abstract concept. Sober highlights this conflict by looking at the values of environmentalists as opposed to those of animal liberationists (Sober 1995). The willingness to value conceptual entities at the expense of individual creatures has been criticised as "environmental fascism" (Regan 1983). Francis Galton foresaw these problems in his discussion of eugenics. He thought we needed to convince present populations that they ought to forego certain individual advantages for the benefit of the species in general (Galton 1909: 68).

It seems wise to guard against entertaining the idea that one could benefit or harm a species, a race or a family without necessarily benefiting or harming any of its particular members. Some of the dangers of abstracting species well-being from that of the individuals which comprise it can be seen in ecological interventions meant to preserve the integrity of a species. One controversial example of this is the culling of a species of duck that occurred in Britain in recent decades (BBC 2003). The ruddy duck, imported to Britain from America in the 1940s, was reported to be threatening the existence of the white-headed duck by interbreeding with it, creating a hybrid species. It was estimated that, in a very short time, the whiteheaded duck would become extinct. Only the hybrid version would survive. An urgent cull was required in order to preserve the white-headed duck species. The attempted messy cull of the invading duck species involved a considerable degree of collateral damage to members of other duck species (including the white-headed duck), as well as to other wildlife in the area. However, this seemed acceptable in view of the fact that the interests of the white-headed species were being furthered.

The idea that species' interests can justify individual suffering is problematic, especially when one considers that no individual duck, whether ruddy or not, would have been killed or would have suffered if the merging of the two species had been allowed to occur. It is more usual to cite the Nazi atrocities in pursuit of a racial ideal as examples of what is wrong with the attempt to benefit a conceptual entity at the expense of individuals. But the ruddy duck example shows how far the abstraction of concepts is prevalent in the way we think. The interests of the individuals are sacrificed for the sake of the greater conceptual entity. This is explicit in nationalistic and patriotic rhetoric, but may be implicit in others. Insofar as the family is regarded as an entity that can be threatened or benefitted, it too is entwined with an implicit ideological framework. In the next section, we explore the relationship between concepts of the family and their ideological underpinnings.

\section{What is the family?}

Although the family is an important concept both privately and politically, there is widespread disagreement about what features are necessary for a group to be recognised as a family: are children a necessary ingredient? Is it necessarily an intergenerational group at all? Can close friends be said to be each other's family? Is a same-sex couple a family? Does the family have a certain form, or does function determine whether a group of intimates is a family? 
It might be that there is no single answer as to what constitutes "the family". Some philosophers argue that we should think about the family as a broad class that can be instantiated in many different forms (Archard 2010: xiv, 4-17). According to Archard, "the family can be minimally defined as a multigenerational group, stably co-habiting, whose adults take primary custodial responsibility for the dependent children" (Archard 2010: 10). Here the family is defined in terms of its function, and the function is the custodial responsibility for children. This will have obvious implications for its form as well: children, for Archard, are a necessary component for a group to be called a family.

Archard's definition does not stipulate anything about the relationships between the adults in a family, other than that they care for children. However, marriage is often regarded as a first step towards the creation of a family. For example, according to the European Convention on Human Rights, "[m]en and women of marriageable age have the right to marry and found a family". A similar formulation is found in Article 16 of the UN Universal Declaration of Human Rights. The Charter of Fundamental Rights of the European Union also encompasses marriage and founding a family but notes that the wording of the relevant Article has been updated to include cases in which "...national legislation recognises arrangements other than marriage for founding a family" (OJC 303 2007). This suggests that marriage is not a necessary condition for the foundation of a family.

According to Article 16 of the Universal Declaration of Human Rights (UDHR),

(1) Men and women of full age, without any limitation due to race, nationality or religion, have the right to marry and to found a family. They are entitled to equal rights as to marriage, during marriage and at its dissolution.

(2) Marriage shall be entered into only with the free and full consent of the intending spouses.

(3) The family is the natural and fundamental group unit of society and is entitled to protection by society and the State.

It is interesting to note here the progression from individuals and their rights ( 1 and 2) to "the family" and its need for protection (3), as well as from normative assertions ("have the right", "shall be entered into") to an empirical claim ("the family is the natural and fundamental group"). The articles of the Declaration refer almost exclusively to the entitlements of "everyone". However, the few exceptions to this are those which pertain to the family and family life: "the family", "motherhood and childhood" (Article 25 (2)), "parents" (Article 26(3)). This is significant, since aside from individual human beings, these conceptual entities (family, motherhood, childhood) are explicitly designated as entities that have entitlements under the act. Moreover, it is motherhood rather than mothers, the family rather than family members, that are to be protected.

In order to protect the family, it is necessary to identify what it is. Concepts of the family are variable, as we have noted. However, a common feature of the institutions and individuals who attach most worth to the family is that they locate this value in a specific conception of what constitutes a family: a mother and a father, preferably married to each other, and their dependent children. This family form is widely assumed to be the natural closest form of intimacy for humans. In the words of Barrett and McIntosh,

It is in the realm of gender, sexuality, marriage and the family that we are collectively most seduced by appeals to the natural. In this realm the shifting 
norms of practice are solidified, some to be sanctified and others condemned. The prevailing form of family is seen as inevitable, as naturally given and biologically determined (Barrett and McIntosh 1991: 27).

It is taken as axiomatic that it is best for children to be conceived within the family and raised by their parents; that this relationship between parents is also the ideal type of intimate relationship between romantic or sexual partners; and that romance and sexual intimacy ought to be at the core of our closest personal relationships as adults (Cutas and Chan 2012). In short, the nuclear family is considered to be the "basic unit of society" (Uzoka 1979, Storrow 2001, Gerstel 2011). This gives the family a normatively loaded status that is justified partly by the intrinsic value accorded to its naturalness, and partly by the associated belief that this 'natural' family structure will be instrumentally better for its members, especially children.

In the West, these beliefs and assumptions have formed the basis for legal recognition and protection of the family. In many jurisdictions, a married woman who gives birth to a child is the default legal mother, and her husband is the legal father. This is the case even where the genetic parents are known to be other people: for example, if a married woman carries a baby in a surrogacy agreement, she is nevertheless the legal mother and her husband the father, despite the fact that neither has a genetic connection with the child. The legal presumption of parenthood in such situations is designed to preserve the integrity of the family unit in changing social and technological environments. Biological relationships in these circumstances are subservient to the continuance of the nuclear family form in the eyes of the law. These protections are not extended in the same way when a family diverges from the perceived ideal form. The less a family resembles the nuclear family norm, the more it is scrutinised (Cutas and Chan 2012). This has been called the prescriptive component of the definition of family: the nuclear family is "how the family ought to be" (Archard 2010: 2-3).

\section{The infertile family}

As we saw in the wording of the UDHR, the family can be treated as an entity with its own needs and entitlements. These needs come into play in the context of fertility treatment where the family is restored to its natural, healthy state, that of two parents and their offspring. Medical interventions are generally concerned with individuals. In medicine, it is supposed to be the patient who is treated or cured. But when families acquire patient status, they gain a rather peculiar power of their own. This is exemplified by the way in which the diagnosis of infertility, which is often required in order to gain access to fertility treatments, is construed. According to the World Health Organisation "clinical" infertility is defined as

a disease of the reproductive system defined by failure to achieve a clinical pregnancy after 12 months or more of regular unprotected sexual intercourse (Zegers-Hochschild and others 2009).

This definition and similar ones function as eligibility criteria for fertility treatment across a number of countries in Europe and beyond. The intercourse referred to here is heterosexual. Sometimes, this is very explicit: according to the UK's National Institute of Clinical Excellence (NICE), clinical assessment should be offered to a woman "of reproductive age [who] has not conceived after 1 year of unprotected vaginal sexual intercourse" (NICE 2013). In a move to broaden access to fertility 
treatments, a series of qualifications have been made to eligibility criteria in some countries. For example, access to fertility treatment in Sweden has been allowed for same-sex female couples since 2005 (SMER 2013) and for single women since 2016 (2015/16:SoU3).

On the other hand, some jurisdictions apply much more stringent restrictions. For example, Gurtin notes that legislation passed in Turkey in 2005 limited access to fertility treatment to married couples. It stipulated that the woman's egg be fertilised with her husband's sperm and then placed "back to the prospective mother's genital organs" (cited in Gurtin 2016). Unmarried patients or those seeking to use donor gametes were thus barred from receiving treatment. Gamete donation, as well as providing fertility treatment to single individuals or same-sex couples, is also outlawed in Italy (Legge 40). A recent legislative proposal in India would allow access to surrogacy only to heterosexual couples married for at least five years (Srivastaval 2016).

By defining infertility in this way, emphasis is displaced from any biological pathology or individual condition, and onto the entity that is the family. It is the family that may or may not suffer from infertility. An illustration of this is that in the UK many health authorities will not offer fertility treatment to couples who already have children (Newham CCG 2015). Biological malfunctions, such as blocked fallopian tubes and azoospermia, are irrelevant here. Rather, it is the deficit in the family (lack of offspring) that is addressed by medical treatment. Infertility is the failure to achieve the nuclear family through sexual intercourse, independently of any associated biological or medical problem.

\section{The family bias in policy}

Once a family comes into being, whether as a result of fertility treatments or natural processes, there is a strong presumption in favour of its continuation. Indeed, its adult members are sometimes regarded as having a moral obligation to secure the family's continued existence. Not only this, but the natural family form is deemed to be intrinsically beneficial for its members, especially children. For example, until 2008, fertility clinics in the UK had to consider a child's "need for a father" before proceeding with treatment. This provision targeted single women and same-sex female couples who might seek to access fertility treatment. It was assumed that such families were suboptimal for children's welfare. By implication, the importance of family structure was more significant than questions about the nature of the relationships involved.

This expected association between the natural family form and the well-being of family members has not been confirmed in practice. Empirical research suggests that what matters most for children's well-being is the quality of relationships within the family and the support that the family receives, rather than family form, whether it is nuclear, whether the parents are married to each other, or the number of parents (Golombok 2015). The regulatory preference for the nuclear family form has started to respond to these findings in some jurisdictions. The abovementioned changes in Swedish access criteria to fertility treatments are one such example. The UK is another one, where the "need for a father" clause has now been replaced with the "need of that child for supportive parenting" (HFEA 1990: 13(5)). 
At the same time, however, scholars from several countries have highlighted the ways in which the value of the family is upheld, even when it clearly is detrimental to the welfare of its members. The overwhelming drive to preserve the nuclear family has been identified as one of the greatest impediments to safety for women in the US (Shoener 2016). The following three examples from Europe and the US illustrate the value placed on reuniting families even when this results in predictable violence and abuse for family members. Sara Shoener, a public health researcher studying services for domestic violence survivors in the US, found that

[t] he truly alarming part $[\ldots]$ is the extent to which the institutions that are intended to assist domestic violence survivors - protection order courts, mental health services, public benefits programs and child custody systems reinforce this stigma [of single motherhood] with both official policies and ingrained prejudices.

Mental health professionals, law enforcement officials, judges and members of the clergy often showed greater concern for the maintenance of a two-parent family than for the safety of the mother and her children. Women who left abusive men were frequently perceived at best as mothers who had not successfully kept their children out of harm's way and at worst as liars who were alienating children from their fathers (Shoener 2014; see also Singal 2014 and Shoener 2016).

On the other side of the Atlantic, a Swedish sociologist writes:

Drawing from a review of all contested contact cases from three primary courts in Sweden during 2010 and 2011, findings suggest that the contact presumption is strong, and generally overrides protection. This norm applies even where there are convictions or explicit reports of child abuse or domestic violence. Priority was neither given to consideration of risk of abuse, nor was a view of children as competent subjects with a right to participation in these proceedings, despite both of these concepts being present in Swedish family law. In cases with 'non-Nordic' fathers however, the contact presumption is less likely to override protection than in cases with 'Nordic' fathers (Bruno 2015).

In social work, a researcher found that:

The cultural demands associated with the position as parent and adult with responsibility for children's needs, seem to make it harder to make visible the vulnerability associated with the position as woman in a heterosexual relationship: the presentation of self as victim-like woman can undermine the presentation of self as responsible adult and parent. (...) Violence tends to be treated as a marginal issue and a gendered understanding of intimate partner violence has been lacking. Instead, parental co-operation and agreements occupy central stage (Eriksson 2014).

These researchers highlight an institutional commitment to the integrity of the family that conflicts with and supersedes the safety of its members. How could it have come about that the family is valued so highly? Okin provides one answer to this question in her analysis of the "sentimental family" (Okin 1982). She shows how the secularisation of society challenged religious underpinnings of the family. Instead of a divinely-ordained family form, ideas of natural design gained sway. At the same time, the economic and social bases of marriage and the family were waning and were being replaced by individual sentiment. According to Okin, " $[t]$ he 
idealizing of the sentimental family [...] provided a new rationale for the subordination of women" (Okin 1982: 65). For Okin, the value accorded to the "sentimental family" is incompatible with an egalitarian understanding of the status of its members.

This tension seems to be confirmed in the examples that we identify in this paper. In the context of human rights legislation, fertility treatments, public health, sociology and social work, evidence can be found that the family is treated as an entity that has needs and entitlements. This is consistent with Warren's criteria for moral status: the family is an entity towards which others can have moral obligations (see the UDHR) and thus we may not treat it anyway we please; it has needs and interests that require protection; it can be ill and receive treatment. It has these entitlements "not merely because protecting it may benefit ourselves or other persons, but because its needs have moral importance in their own right" (Warren 1997: 3). If women and children, or other family members, have full moral status, and the family supersedes their interests, what does that say about the status of the family?

\section{Conclusion}

Over the past centuries, prevailing ideas about who or what has moral status have evolved. In the past, only a subset of human beings were regarded as having full moral status: white, male, adult. Our more modern, generous approach may be commendable, in accommodating women and children and embracing those of all ethnicities and social strata, as well as non-human animals. But if, as we have shown, the moral status of the family can supersede that of its individual members, this seems to imply that there exists an entirely new category of moral status - that of the family - that is higher than full moral status.

As we showed above, human rights documents, eligibility criteria for fertility treatments, and representatives of the State converge in awarding "the family" special status beyond that of its members - and sometimes against them. This is difficult to reconcile with contemporary Western values that, in theory at least, regard women and children as having moral status, and place a high degree of importance on the value of facts and evidence in determining what is best for those who are vulnerable. Ultimately, the demands of the value placed on the family and the moral status of its members might be irreconcilable. If our policies and values are to be consistent with the interests of individual people, the family may have to undergo a change in moral status.

\section{Notes}

1 It should be noted here that Warren did not include inanimate objects or conceptual entities in her concept of moral status. Thus, Warren herself would probably object to ascribing moral status to the family.

\section{References}

Archard, D. (2010). The Family. A Liberal Defence. London, Palgrave Macmillan. https://doi.org/10.1057/9780230294578 
Barrett, M., McIntosh, M. (1991). The Anti-Social Family. London, Verso.

BBC (2003, March 1 ${ }^{\text {st }}$ ), Duck Cull Ruffles Feathers. Retrieved March 2017, from http://hnews.bbc.co.uk/1/hi/uk/2810119.stm

Brennan, S., Noggle R. (1997). The Moral Status of Children: Children's Rights, Parents' Rights, and Family Justice. Social Theory and Practice 23(1): 1-26. https://doi.org/10.5840/soctheorpract19972311

Bruno, L. (2016). Ofridstid. Fäders våld, staten och den separerade familjen (Doctoral dissertation, Uppsala Universitet). Uppsala: Uppsala Universitet.

Cutas, D., Chan, S. (eds) (2012). Families - Beyond the Nuclear Ideal. London: Bloomsbury Academic.

DeMause, L. (1974). The History of Childhood. New York: Harper and Row.

Eriksson, M. (2014). Mothers as a Vulnerable Group of Women Subjected to Violence. Social Dialogue Magazine 8: 10-15.

Galton, F. (1909). Essays in Eugenics. London, Eugenics Education Society.

Gerstel, N. (2011). Rethinking Families and Community: the Color, Class, and Centrality of Extended Kin Ties. Sociological forum 26(1): 1-20. https://doi.org/10.1111/j.1573-7861.2010.01222.x

Gheaus, A. (2017). What Abolishing the Family Would Not Do. Critical Review of International Social and Political Philosophy (forthcoming).

Gurtin, Z. (2016). Patriarchal Pronatalism: Islam, Secularism and the Conjugal Confines of Turkey's IVF Boom. Reproductive Biomedicine \& Society Online 2: 39 - 46. https://doi.org/10.1016/j.rbms.2016.04.005

Human Fertilisation and Embryology Act (HFEA) 1990, as amended. Retrieved March 2017, from http://webarchive.nationalarchives.gov.uk/20130107105354 http://www.dh.gov.uk/prod_consum_dh/groups/dh_digitalassets/@dh/@en/d ocuments/digitalasset/dh_080206.pdf

Legge 40, 19 February 2004. Retrieved March 2017, from http://www.camera.it/ parlam/leggi/04040l.htm

Munoz-Dardé, V. (1999). Is the Family to be Abolished Then? Proceedings of the Aristotelian Society XCIX: 37-56. https://doi.org/10.1111/1467-9264.00044

National Institute of Clinical Excellence. (2013). Fertility Problems: Assessment and Treatment. Retrieved March 2017, from http://nice.org.uk/guidance/ cg156/chapter/Recommendations\#defining-infertility

Newham CCG Clinical Fertility policy (2015). Retrieved March 2017, from http://newhamccg.nhs.uk/Downloads/News-and-Publications/Policies-andprocedures/NHS-Newham-CCG-Clinical-Fertility-Policy-September2015.pdf

Okin, S. (1989). Justice, Gender and the Family. New York: Basic Books.

Regan, T. (1983). The Case for Animal Rights. Berkeley: University of California Press.

Rolston, H, III. (2002). Values in and Duties to the Natural World. In Schmidtz, D. \& Willott, E. (eds), Environmental Ethics: What Really Matters, What Really Works. New York: Oxford University Press.

Shoener, S. (2014). Two-Parent Households Can Be Lethal. Domestic Violence and Two-Parent Households, New York Times, June 21 ${ }^{\text {st }}$. Retrieved March 2017, from http://nytimes.com/2014/06/22/opinion/sunday/domestic-violence-andtwo-parent-households.html 
Shoener, S. (2016). The Price of Safety. Hidden Costs and Unintended Consequences for Women in the Domestic Violence Service System. Nashville: Vanderbilt University Press.

Singal, J. (2014). How Our Obsession With Marriage Enables Abuse. New York Magazine, June 24. Retrieved March 2017, from http://nymag.com/ scienceofus/2014/06/how-our-obsession-with-marriage-enables-abuse.html

Srivastaval, B. (2016) Anti-surrogacy bill dashes hopes of aspiring parents, The Times of India, September 20. Retrieved March 2017, from http://timesofindia.indiatimes.com/city/ranchi/Anti-surrogacy-bill-dasheshopes-of-aspiring-parents/articleshow/54418447.cms

SMER, Assisterad befruktning - etiska aspekter. Rapport 2013:1. Retrieved November 2016, from http://smer.se/wp-content/uploads/2013/02/ Smer_rapport_2013_1_webb.pdf

Sober, E. (1986). Philosophical Problems for Environmentalism, in Norton, B.G. (ed), The preservation of species. Princeton: Princeton University Press.

Stanford Encyclopedia of Philosophy. (2013). The Grounds of Moral Status. Retrieved March 2017, from http://seop.illc.uva.nl/entries/grounds-moralstatus/

Storrow, R. (2001). The Policy of Family Privacy: Uncovering the Bias in Favour of Nuclear Families in American Constitutional Law and Policy Reform. Missouri Law Review 66 (3): 527-621. https://doi.org/10.2139/ssrn.289677

Taylor, T. (1986). Respect for Nature: A Theory of Environmental Ethics. Princeton, NJ: Princeton University Press.

United Nations. (1989). Convention on the Rights of the Child, Geneva: United Nations. Retrieved March 2017, from http://ohchr.org/EN/ ProfessionalInterest/Pages/CRC.aspx

Uzoka, A. (1979). The Myth of the Nuclear Family: Historical Background and Clinical Implications. American Psychologist 34(11): 1095-1106. https://doi.org/10.1037/0003-066X.34.11.1095

Varner, G.E. (1998). In Nature's Interests? Interests, Animal Rights, and Environmental Ethics. New York: Oxford University Press.

Zegers-Hochschild, F., Adamson G.D., de Mouzon J., Ishihara, O., Mansour, R., Nygren, K., WHO (2009). International Committee for Monitoring Assisted Reproductive Technology (ICMART) and the World Health Organisation (WHO) Revised Glossary of ART Terminology, Fertility and Sterility 92(5): 1520-24. https://doi.org/10.1016/j.fertnstert.2009.09.009

2015/16:SoU3, Assisterad befruktning för ensamstående kvinnor. Retrieved March 2017, from http://data.riksdagen.se/fil/2AE1B1D4-EC9C-4F92-AE93-FC624D $719 \mathrm{E} 78$ 